\title{
Air Damping Characteristics of Integrated Accelerometers with a Single-Side Air Gap
}

\author{
H. Muro, S. Kiyota, S. Uchikoshi and R. Himeno \\ Nissan Motor Co., Lid. \\ 1, Natsushima-cho, Yokosuka 237, Japan
}

\begin{abstract}
Summary
In this paper, damping characteristics of piezoresistive integrated silicon accelerometers, in which a micromachined seismic mass is suspended by four narrow beams from the surrounding frame that incorporates peripheral circuitry and squeeze film damping effect is provided by a single-side air gap under the seismic mass, were analyzed and numerically calculated. The output waveforms for applied sinusoidal accelerations are different from those of accelerometers with symmetrical air-gap structure when subject to large accelerations. The calculated results are compared with measured characteristics of the fabricated devices.
\end{abstract}

Keywords: accelerometer, micromachining, integrated sensor, air damping and squeeze-film effect

\section{INTRODUCTION}

With increasing needs for low cost accelerometers for automotive uses, typified by airbag systems, various types of silicon accelerometers using micromachining technology have been developed in recent years[1]-[8]. They have many attractive features concerning the size and productivity with batch fabrication process. Moreover signal processing circuitry can be integrated on the same sensor chip in ordor to facilitate more compact packaging and improve the reliability[6]-[10].

The piezoresistive accelerometers can be easily fabricated by forming the circuit on a silicon substrate using the conventional IC process and etch the substrate from the back side to construct a seismic mass suspended from the surrounding frame by thin narrow beams [7]-[9]. Electrochemical etching techniques are often used to control the beam thickness, mostly in combination with bipolar process where n-type epilayer is used as the beams [11]. The integration technology is also applied for capacitive ones, although mainly for those using surface micromachining technologies[6].

In developing the available silicon micromachined accelerometers, technologies of oil damping or air damping are usually used to supress the beam resonance and attain sufficient shock resistivity. Oil damping requires no additional structures and is realized only by immersing the beam and the mass in damping liquid, such as silicone oil, which, however, has large temperature dependence of viscosity[7],[8].

On the other hand, air damping is provided by the squeezed-film effect in a narrow air gap between the moving mass and the planes opposed to it[1]-[4]. The air gaps with only a few micronmeter width can be formed by bonding a base plate and a cap plate, each with depressions faced to the mass, to both sides of silicon micromachined substrate as shown in Fig.la. This structure is completed during the wafer fabrication process and the divided chips can be packaged easily compared with the oil damping ones.

For the air damped accelerometers with such a sandwich structure most of the surface area of the frame is consumed for bonding of the cap plate, which makes it difficult to integrate peripheral circuitry on the frame and consequently results in large increase of the chip size for integrating the circuitry.

An alternative choice on air damping in accelerometers is to form only a single air gap at the bottom side of the mass and utilize the frame surface for circuit area as shown in Fig.lb, where the damping may be alleviated for large accelerations when the mass moves away from the base plate. In this paper, the damping characteristics of the accelerometers with a single side air gap are studied theoretically and experimentally.

\section{DAMPING CHARACTERISTICS}

The dynamic behavior of the mass-spring system, found in the silicon accelerometer, is determined by the following motion equation [1],[2] :

$\mathrm{m} \frac{\mathrm{d}^{2} \mathrm{x}}{\mathrm{dt}^{2}}+\lambda \frac{\mathrm{dx}}{\mathrm{dt}}+\mathrm{kx}=\mathrm{m} \alpha(\mathrm{t}) \quad \cdot \cdot(1)$

where $\mathrm{m}$ is mass, $\lambda$ is the viscosity damping coefficient, $k$ is the spring constant of the beams, $x$ is the displacement of the mass, and $\alpha(t)$ is the applied acceleration. The viscosity damping is caused by the squeeze film effect in the air gap and can be calculated by solving the Navier-Stokes equation under the assumption of small Reynolds numbers [12],[13]. The 


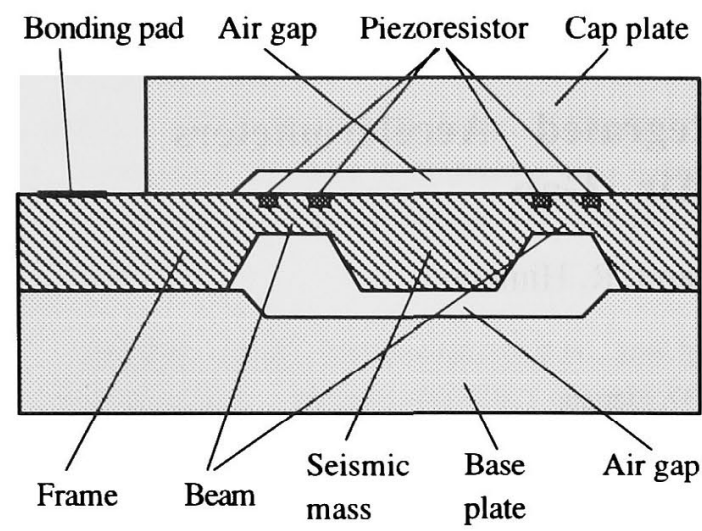

(a) Accelerometer with a cap plate

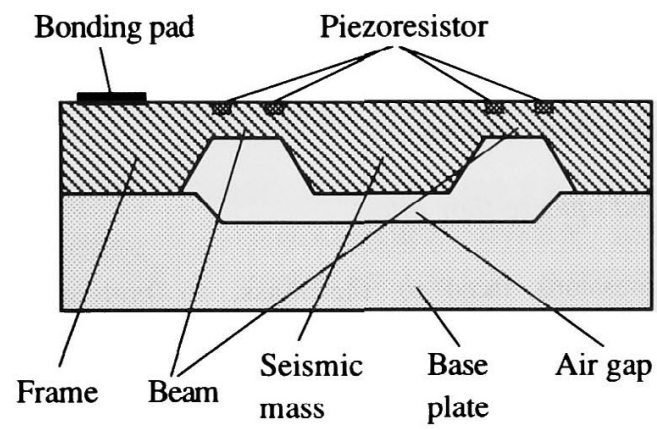

(b) Accelerometer without a cap plate

Fig.1 Cross-sectional structures of the silicon micromachined accelerometers with air gaps.

viscosity damping coefficient, $\lambda$, is expressed by the form of an infinite series expansion using a squeeze number, $\sigma$, as a parameter :

$$
\sigma=\frac{12 \mu \omega 1^{2}}{\mathrm{~d}^{2} \mathrm{P}_{\mathrm{a}}}
$$

in which $\mathrm{P}_{\mathrm{a}}$ is the ambient gas pressure, $\omega$ is the frequency, $\mu$ is the viscosity coefficient, $d$ is the gap width, and $l$ is a characteristic length which in the case of a square mass equals the side length of the mass. At low squeeze numbers, where the oscillation of the mass is slow enough so that compressibility effect can be neglected, the damping coefficient for parallel square plates becomes [14],[15] :

$$
\lambda=\frac{0.42 \mu \mathrm{S}^{2}}{\mathrm{~d}^{3}}
$$

in which $S$ is the area of the plate.

The characteristics of squeeze film damping will be modified when the displacement of the mass become significant with respect to the gap width. The viscosity damping coefficient with a large displacement can be calculated by multiplying it by a displacement factor as [15] :
$F_{D}=(1-\varepsilon)^{-\frac{3}{2}}$

where $\varepsilon$ is the ratio of the mass displacement to the gap width.

Although these analyses are mainly focused on symmetrical damping for sinusoidal accelerations, the accelerometers with a single side air gap as shown in Fig. 1b will be asymmetrically damped for large accelerations, that is, the moving mass is less damped when displaced away from the base plate. In order to evaluate this effect on the damping characteristics by simple numerical calculations, the motion equation (1) was modified by replacing the gap width, $d$, used in the damping coefficient by that under the mass displacement, $x+d$, resulting the following equation.

$$
\begin{aligned}
& \mathrm{m} \frac{\mathrm{d}^{2} \mathrm{x}}{\mathrm{d} \mathrm{t}^{2}}+\frac{\lambda}{\left(1+\frac{\mathrm{x}}{\mathrm{d}}\right)^{3}} \frac{\mathrm{dx}}{\mathrm{dt}}+\mathrm{kx}=\mathrm{m} \alpha(\mathrm{t}) \cdot \cdot(5) \\
& \text { or } \\
& \frac{\mathrm{d}^{2} \mathrm{x}}{\mathrm{dt}^{2}}+\frac{\beta}{\left(1+\frac{\mathrm{x}}{\mathrm{d}}\right)^{3}} \frac{\mathrm{dx}}{\mathrm{dt}}+\omega_{0}^{2} \mathrm{x}=\alpha(\mathrm{t}) \cdot \cdots(6)
\end{aligned}
$$

where $\omega_{0}$ is the resonant frequency $=(\mathrm{k} / \mathrm{m})^{1 / 2}$ and $\beta$ is the ratio of the viscosity damping coefficient to the mass $=\lambda / \mathrm{m} . \quad \beta$ is related to the $3 \mathrm{~dB}$ cutoff frequency, $\omega_{\alpha}$, through the equation :

$$
\beta^{2}=\frac{\omega_{0}^{4}+2 \omega_{\alpha}{ }^{2} \omega_{0}{ }^{2}-\omega_{\alpha}{ }^{4}}{\omega_{\alpha}{ }^{2}}
$$

The damping characteristics for sinusoidal accelerations were calculated by solving the differential equation (6).

\section{DEVICE FABRICATION}

The prototype of the integrated accelerometer was designed to detect medium range acceleration of about $50 \mathrm{G}$ with frequency response up to several hundred $\mathrm{Hz}$. Fig.2 shows a photograph of the fabricated accelerometer chip. Silicon seismic mass with a area of $1.5 \mathrm{~mm} \times 1.5 \mathrm{~mm}$ and weight of about $1.4 \mathrm{mg}$ is suspended from the surrounding support by two pairs of thin silicon beams from both sides. The beams are 400 $\mu \mathrm{m}$ long, $340 \mu \mathrm{m}$ wide, $9 \mu \mathrm{m}$ thick and arranger along the $\langle 110\rangle$ direction of the silicon substrate. A pair of p-type piezoresistors are formed on each beam near both ends of the beam to construct a Wheatstone bridge circuit with cross-sensitivity compensation. The applied acceleration is detected piezoresistively through $\varepsilon$ change in the bridge output voltage.

On the frame, the peripheral circuitry is integrated for signal conditioning of the bridge output, whost sensitivity is about $150 \mu \mathrm{V} / \mathrm{G}$. These circuits are former by conventional bipolar process, whose epilayer is alsi used as the beams by applying electrochemical etching. The fabrication process of this integrated acceleromete: is shown in Fig.3.

(a) The starting material is (100) $10 \Omega \mathrm{cm}$ both-sids 


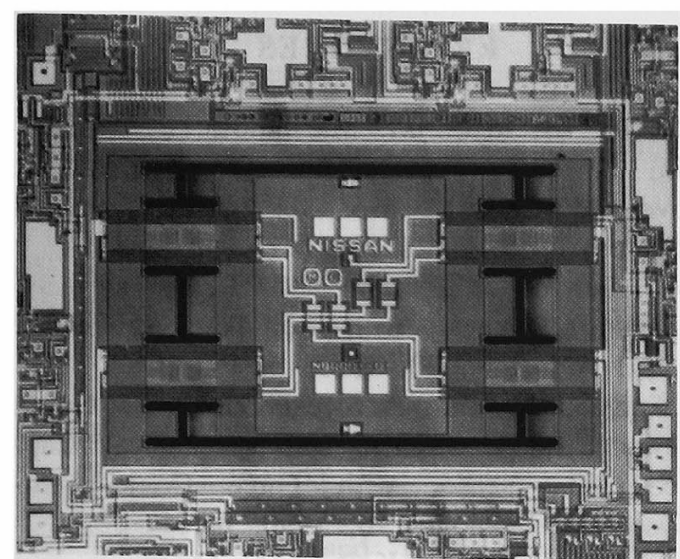

Fig.2 A photograph of the fabricated integrated accelerometer.

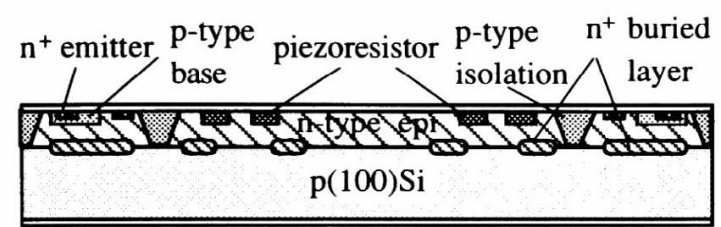

(a)

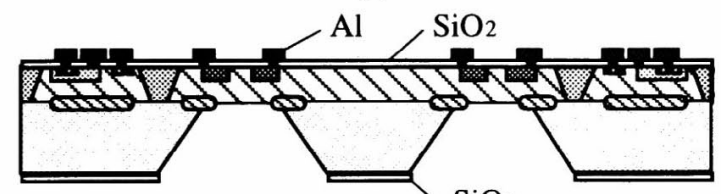

(b)

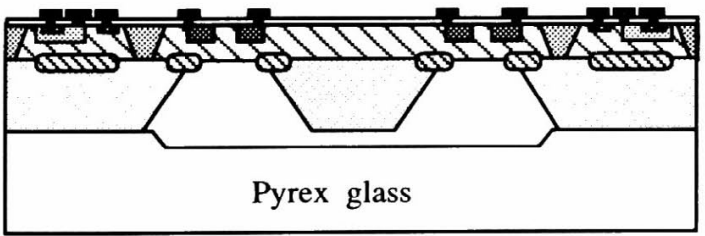

(c)

Fig.3 A fabrication process flow diagram of the integrated accelerometer.

polished p-type silicon substrate with a $2 \Omega \mathrm{cm}, 9 \mu \mathrm{m}$ thick n-type epilayer. Several diffusions are performed to form bipolar circuitry. The piezoresistors are formed by implanting boron with a dose of $3 \times 10^{15} / \mathrm{cm}^{2}$.

(b) After forming aluminum interconnections, the back side silicon oxide layer is patterned. The p-type substrate is electrochemically etched from the back side by hydrazine solution using the three-electrode method. During the etching process n-type epilayer was positively biased to create an etch stop and the beams. (c) Pyrex glass is used for the base plate, where grooves are etched in the regions of the air gap by buffered HF. The glass substrate is bonded to the sculptured silicon substrate using the anodic bonding technology, resulting in an air gap of about $1.8 \mu \mathrm{m}$ width under the released mass.

\section{EXPERIMENTS}

The bonded wafers were divided and each chip was mounted and sealed at atmospheric pressure with a standard metal package. The packaged sensor was attached to a shaker and the output waveform from the senor was monitored by a digitizing oscilloscope. The vibration frequency was scanned from $100 \mathrm{~Hz}$ to $10 \mathrm{kHz}$ with acceleration level up to $100 \mathrm{G}\left(980 \mathrm{~m} / \mathrm{s}^{2}\right)$. The measured outputs were expressed in gravity unit, G, by dividing them by the sensitivity measured at input acceleration of $10 \mathrm{G}$.

Fig.4 and Fig.5 show the measured output waveforms of the fabricated accelerometer with vibration conditions of $500 \mathrm{~Hz} / 50 \mathrm{G}$ and $2 \mathrm{kHz} / 100 \mathrm{G}$, respectively. The waveforms calculated by the equation (6) with the fitting parameters of $\beta=143 \mathrm{kHz}$ and $\omega_{0}=50 \mathrm{kHz}$, which agree reasonably with the values calculated using the device dimensions, are also shown by dotted lines. As the amplitude and frequency of the input accelerations increase, the air damping effect increases, resulting in asymmetrical output waveforms. These asymmetrical responses were evaluated by measuring the output amplitudes of maximum and minimum values as shown in Fig.6. The frequency responses of measured amplitudes, $\mathrm{V}_{\mathrm{H}}$ and $\mathrm{V}_{\mathrm{L}}$, at input accelerations of $50 \mathrm{G}$ and $100 \mathrm{G}$ were plotted in Fig.7 with the corresponding calculated curves. As the acceleration frequency increases, $\mathrm{V}_{\mathrm{L}}$ begins to decay at frequency higher than $500 \mathrm{~Hz}$, while the frequency response of extends beyond $1 \mathrm{kHz}$,

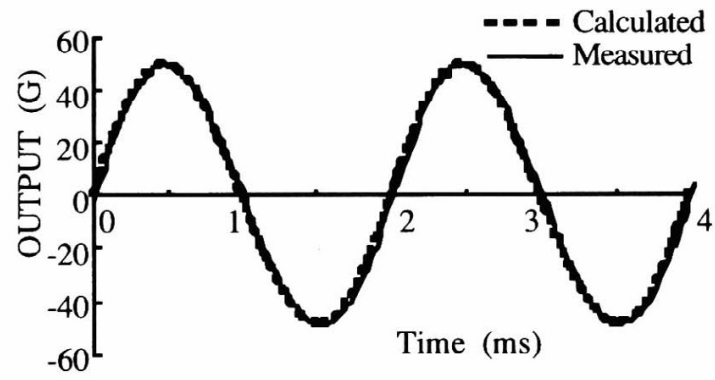

Fig.4 Output waveforms at $500 \mathrm{~Hz} / 50 \mathrm{G}$.

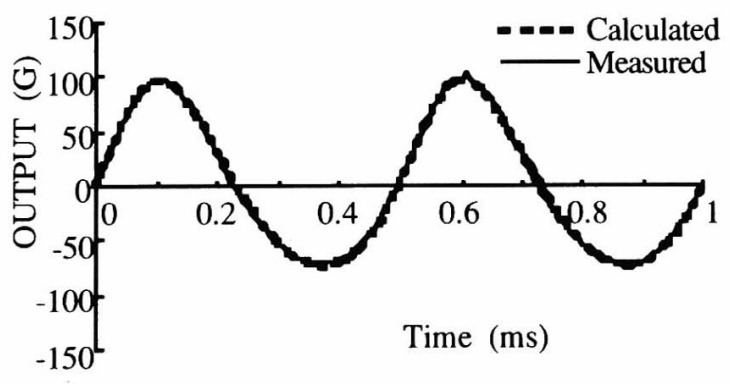

Fig.5 Output waveforms at $2 \mathrm{kHz} / 100 \mathrm{G}$. 


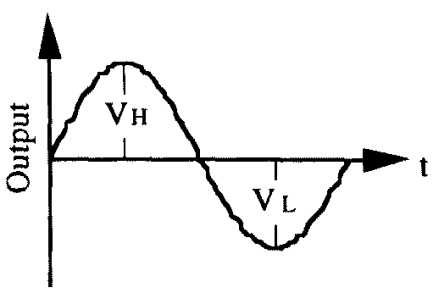

Fig.6 Waveform parameters, $\mathrm{V}_{\mathrm{H}}$ and $\mathrm{V}_{\mathrm{L}}$.

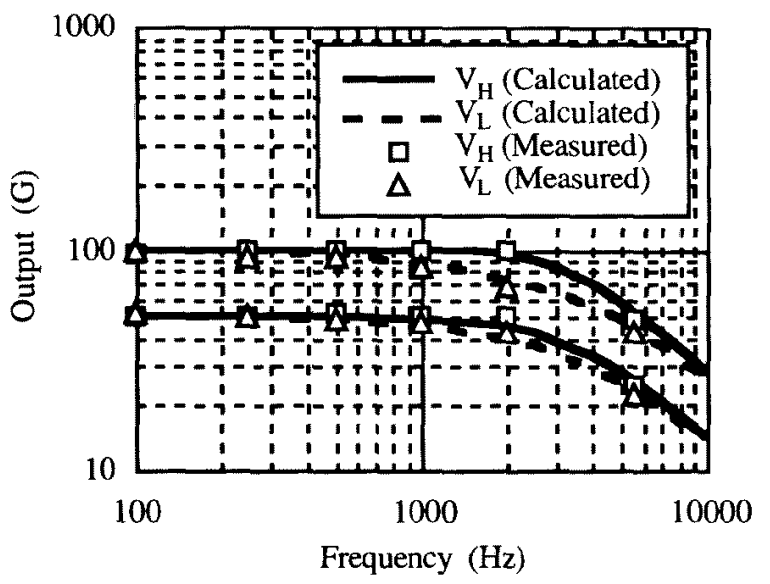

Fig.7 Frequency responses of $\mathrm{V}_{\mathrm{H}}$ and $\mathrm{V}_{\mathrm{L}}$ at $50 \mathrm{G}$ and $100 \mathrm{G}$ accelerations.

whose $3 \mathrm{~dB}$ cutoff frequencies lie in $2 \sim 4 \mathrm{kHz}$. (These frequency bandwidths are sufficient for various practical applications such as airbag systems.) As expected, $V_{H}$ and $V_{L}$ curves behave as if they had different damping coefficients, where the difference increased with input accelerations. The measured results agree reasonably with the calculated ones, although there are considerable measurement errors at frequencies higher than $2 \mathrm{kHz}$ due to the parasitic resonances of the attachment or the shaker itself.

\section{CONCLUSIONS}

In this paper, a piezoresistive integrated accelerometers with a single side air gap under the seismic mass have been described. The damping characteristics of such accelerometers were numerically calculated simply by modifying the motion equation. The prototypes of such accelerometers were designed and fabricated, whose measured results agreed reasonably with the calculated ones.

\section{ACKNOWLEDGEMENTS}

The authors wish to thank the members of the Electronics Production Department, Nissan Motor Co., Ltd. for their help in the fabrication of the devices.

(Manuscript received March 29, 96, revised August 30, '96)

\section{REFERENCES}

(1)S. Suzuki, M. Miki, M. Matsumoto, B. Kloeck, S. Kuragaki, K. Sato and A. Koide, "Semiconductol Capacitive-type Crash Sensor for Airbag Systems", Micro System Technologies 92, 1992, pp.383-392.

(2)H. V. Allen, S. C. Terry and D. W. De Bruin, "Accelerometer Systems with Self-Testable Features", Sensors and Actuators, 20, 1989, pp.153-161.

(3)H. F. Schlaak, F. Arndt, A. Steckenborn, H. J. Gevatter, L. Kiesewetter and H. Grethen, "Micromechanical Capacitive Acceleration Sensor with Force Compensation", Micro System Technologies 90, 1990, pp.617-622.

(4)H. Seidel, H. Riedel, R. Kolbeck, G. Muck, W. Kupke and M. Koniger, "Capacitive Silicon Accelerometer with Highly Symmetrical Design", Sensors and Actuators, A21-A23, 1990, pp.312-315.

(5)Lj. Ristic, R. Gutteridge, J. Kung, D. Koury, B. Dunn and H. Zunino, "A Capacitive Type Accelerometer with Self-Test Feature Based on a Double-Pinned Polysilicon Structure", Transducers'93, Yokohama, Japan, 1993, pp.810-813.

(6)T. A.Core, W. K. Tsang and S. J. Sherman, "Fabrication Technology for an Integrated Surface-Micomachined Sensor", Solid State Technology, Octorber 1993, pp.39-47. (7)M. Mutoh, K. Fujita, T. Inayoshi and M. Iyoda, "Toyota Air Bag Sensor", SAE PAPER 911270, 1991, pp.89-96.

(8)H. Muro, A. Hanamura, T. Mitamura and S. Kiyota, "Integrated Piezoresistive Accelerometers with OilDamping", Micro System Technologies 92, 1992, pp.233-241.

(9)W. Riethmuller, W. Benecke, U. Schnakenberg and B. Wagner, "A Smart Accelerometer with On-Chip Electronics Fabricated by a Commercial CMOS Process", Sensors and Actuators, A31, 1992, pp.121-124.

(10)Y. Matsumoto and M. Esashi, "Integrated Silicon Capacitive Accelerometer with PLL Servo Technique", Sensors and Actuators, A39, 1993, pp.209-217.

(11)M. Nakamura, K. Murakami, H. Nojiri and T. Tominaga, "Novel Electrochemical Micro- Machining and its Application for Semiconductor Acceleration Sensor IC", Transducers'87, Tokyo, Japan, 1987, pp.112-115.

(12)J. J. Blech, "On Isothermal Squeeze Films", J. Lubrication Technology, 105, 1983, pp.615-620.

(13)M. H. Sadd and A. K. Stiffler, "Squeeze Film Dampers: Amplitude Effects at Low Squeeze Numbers", J. Eng. Ind., Trans. ASME, 97B, 1975, pp.1366-1370. (14)M. Andrew, I. Harris and G. Tuner, "A Comparison of Squeeze-Film Theory with Measurements on a Microstructure", Sensors and Actuators, A36, 1993, pp.79-87.

(15)J. B. Starr, "Squeeze-Film Damping in Solid- State Accelerometers", IEEE Solid-State Sensor and Actuator Workshop, Hilton Head Island, SC, USA, 1990, pp.44-47. 
Hideo Muro $\mathrm{He}$ received his B.S. and M.S.

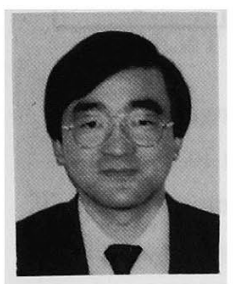
degrees in electrical engineering from Tokyo university, Tokyo, Japan, in 1976 and 1978, respectively. Since joining Nissan Motor Co., Ltd. in 1981, he has been engaged in developing silicon sensors.

Shigeyuki Kiyota $\mathrm{He}$ received his B.S. and M.S.

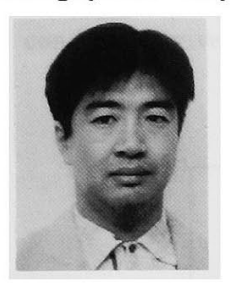

degrees in electrnnic engineering from Keio university, Kanagawa, Japan, in 1987 and 1989, respectively. He has been working at Nissan Motor Co., Ltd. since 1989.

Susumu Uchikoshi He received his B.S. and

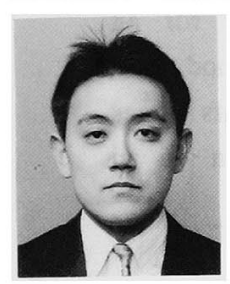

M.S. degrees in physics from Keio university, Kanagawa, Japan, in 1989 and 1991, respectively. He has been working at Nissan Motor Co., Ltd. since 1991

Ryutaro Himeno He received his B.S. and M.S.

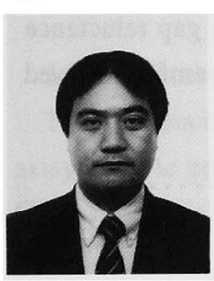

degrees in electrical engineering from Kyoto university, Kyoto, Japan, in 1977 and 1979, respectively. He joined Nissan Motor Co., Ltd. in 1979. He served as a researcher at the Institute of Space and Astronautical Science, Japan, from 1984 until 1986. He received his D.E. degree in applied physics from Tokyo university, Tokyo, Japan, in 1988. He is currently a Senior Researcher in Computational Fluid Dynamics at Nissan Research Center. 